\title{
Analisis Luas Ruangan Berdasarkan Kebutuhan Rak Di Ruang Penyimpanan Berkas Rekam Medis Rawat Jalan Di Rumah Sakit Umum Madani Medan Tahun 2019
}

\author{
${ }^{1}$ Puput Melati Hutauruk, ${ }^{2}$ Fince Rachmat Zega
}

Program Studi D-IV Manajemen Informasi Kesehatan, Universitas Imelda Medan

\begin{tabular}{l}
\hline Article Info \\
\hline Article history: \\
Received Feb24, 2020 \\
Revised Feb 25, 2020 \\
Accepted Feb28, 2020 \\
\hline
\end{tabular}

Keywords:

Medical Records

Storage Shelves

Room Area

\begin{abstract}
ABSTRAK
Medical records are stored in a storage rack to maintain confidentiality, avoid damage and make it easier for officers to retrieve and return medical records. In order for the service to be effective and efficient, in addition to requiring adequate storage shelves, storage rooms that can also contain storage shelves are needed so that they can store patient medical record files for a certain period of time for future examinations and facilitate retrieval by officers. Therefore the researcher aims to determine the area of the room based on the needs of the current shelves at the Medan Madani General Hospital in 2019. This research uses a quantitative descriptive method by describing the results of the research as it is and comparing with the theory then conclusions are drawn. The subjects in this study were the outpatient medical record file storage room, and the object in this study was the medical record file and outpatient storage rack. The results of this study indicate that the number of outpatient medical record file storage racks in Medan Madani General Hospital is 8 shelves with an area of $18.99 \mathrm{~m} 2$. If the hospital currently has 8 shelves, the hospital needs to provide 10 more shelves so the room area becomes $48.82 \mathrm{~m} 2$ so that the room area can be fulfilled and can load the shelves according to the hospital's needs so that it does not make it difficult for the storage staff to retrieve or return the patient's medical record .
\end{abstract}

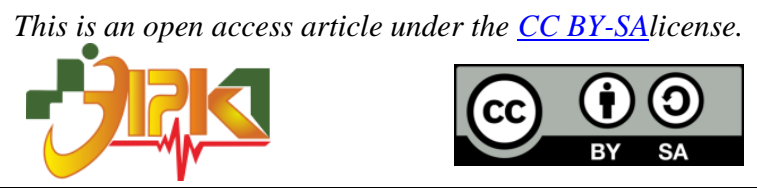

\section{Corresponding Author:}

Puput Melati Hutauruk,

Program Studi D-IV Manajemen Informasi Kesehatan,

Universitas Imelda Medan,

Jl. Bilal No. 52 Kelurahan Pulo Brayan Darat I Kecamatan Medan Timur, Medan - Sumatera Utara.

Email: puputmelati.pm71@gmail.com

\section{PENDAHULUAN}

Setiap sarana pelayanan kesehatan diwajibkan menyelenggarakan rekam medis, salah satu manfaatnya sebagai bukti pelayanan kesehatan yang dilakukan di rumah sakit. Dalam Undang-undang No. 29 tahun 2004 tentang praktik kedokteran pasal 46 ayat (1) menegaskan bahwa dokter dan dokter gigi wajib membuat rekam medis dalam menjalankan praktik kedokteran. Rekam medis yang telah diisi lengkap oleh pemberi pelayanan kesehatan selanjutnya akan diolah menjadi laporan kemudian akan disimpan ke ruang penyimpanan atau filing. Penyimpanan merupakan kegiatan menyimpan, penataan atau penyimpanan (storage) berkas rekam medis untuk mempermudah pengambilan kembali (retrieval) 
(Rustiyanto, 2011). Rekam medis disimpan dalam rak penyimpanan agar terjaga kerahasiaanya, terhindar dari kerusakan dan mempermudah petugas dalam pengambilan dan pengembalian rekam medis. Agar pelayanan menjadi efektif dan efesien, selain memerlukan rak penyimpanan yang cukup, juga perlu ruangan penyimpanan yang bisa memuat rak penyimpanan tersebut agar dapat menyimpan rekam medis pasien dalam jangka waktu tertentu guna pemeriksaan diwaktu yang akan datang dan memudahkan pengambilan kembali oleh petugas.

Ruang penyimpanan yang cukup memang dibutuhkan semua rumah sakit agar pelayanan menjadi efektif dan efesien. Namun tidak semua rumah sakit memenuhi hal tersebut. Salah satu rumah sakit di Indonesia yang memiliki masalah dalam ruang penyimpanan adalah RSUD dr. Soekardjo Kota Tasikmalaya. Menurut penelitian (Putri dkk, 2015) dan (Ritonga \& Ritonga, 2018) tentang kebutuhan rak dan ruangan penyimpanan. Ruangan penyimpanan di RSUD dr. Soekardjo Kota Tasikmalaya memiliki tata ruang yang kurang efektif. Ruangan penyimpanan Rawat Jalan memiliki 10 rak penyimpanan dokumen rekam medis. Berdasarkan hasil penelitian yang dilakukan untuk ukuran panjang rak semua sama akan tetapi sebelumnya petugas rekam medis pernah menambahkan 2 rak baru yang disimpan disatukan berdampingan sehingga tata ruang yang ada menjadi semakin sempit. Oleh karena itu peneliti menyarankan baiknya kondisi ruangan disesuaikan dengan data antropometri petugas penyimpanan rawat jalan sehingga petugas merasa lebih nyaman dalam melakukan pekerjaannya.

Menurut Penelitian (Silalahi, 2016) yang berjudul Tinjauan Prosedur Penyimpanan Rekam Medis di Rumah Sakit Jiwa Provinsi Sumatera Utara di rumah sakit tersebut juga mengalami hal yang sama yakni jumlah rak penyimpanan rekam medis kurang dan jarak antara rak penyimpanan rekam medis juga sangat sempit sehingga menyulitkan petugas rekam medis ketika mengambil berkas rekam medis pasien akibatnya pelayanan menjadi tidak efektif dan efisien. Berdasarkan hasil penelitian sistem penyimpanan dengan sistem sentralisasi yang ada di Rumah Sakit Jiwa Provinsi Sumatera Utara Medan belum disusun dengan rapi. Dimana rekam medis yang disimpan tidak cukup untuk masuk kedalam rak penyimpanan rekam medis, yang disebabkan karena luas ruang penyimpanan rekam medis yang mengakibatkan rak penyimpanan rekam medis tidak dapat ditambah kedalam ruang penyimpanan rekam medis. Sehingga banyak status rekam medis ditumpukkan diatas status yang telah disusun rapi sesuai dengan nomor rekam medisnya. Pada akhirnya peneliti menyarankan perlu penambahan pada rak dan luas ruangan penyimpanan yang bertujuan agar status yang telah disusun secara sejajar dan sesuai nomor urutan rekam medis tidak ditumpukkan diatas status yang telah disusun sehingga akan terlihat lebih rapi.

Berdasarkan survei awal yang di lakukan oleh peneliti diruang penyimpanan di RSU Madani Medan diperoleh informasi bahwa sistem penyimpanan di rumah sakit tersebut menggunakan sistem desentralisasi, yaitu dengan cara pemisahan antara rekam medis rawat jalan dengan rekam medis rawat inap sehingga penyimpanan berkas rekam medis tidak berpusat di satu tempat saja. Dari pengamatan dilapangan, jumlah rak di ruang penyimpanan masih kurang akibatnya sebagian berkas rekam medis diletakkan di lantai. Luas ruangan penyimpanan berkas rekam medis rawat jalan di RSU Madani Medan sangat kecil yakni $18,99 \mathrm{~m}^{2}$ dan memuat rak penyimpanan sebanyak 8 rak sehingga Jarak antara rak penyimpanan sempit yakni $54 \mathrm{~cm}$ dan tidak sesuai standar menurut Depkes yang dianjurkan selebar $90 \mathrm{~cm}$ sehingga hanya bisa memuat 1 orang petugas penyimpanan. Ini dapat mempersulit petugas penyimpanan dalam pengambilan maupun pengembalian rekam medis serta pendistribusian ke poliklinik menjadi terlambat.

Penelitian sebelumnya yang berkaitan dengan luas ruangan berdasarkan kebutuhan rak di ruang penyimpanan berkas rekam medis menyatakan agar luas ruangan dapat tercukupi dan dapat memuat rak sesuai kebutuhan rumah sakit sehingga tidak menyulitkan petugas penyimpanan dalam pengambilan maupun pengembalian rekam medis pasien (Lubis \& 
Handayani, 2018).

Berdasarkan Uraian di atas maka penulis tertarik untuk melakukan penelitian mengenai "Analisis Luas Ruangan Berdasarkan Kebutuhan Rak di Ruang Penyimpanan Berkas Rekam Medis Rawat Jalan di RSU Madani Medan 2019”. Berdasarkan latar belakang di atas penulis merumuskan pemasalahan sebagai berikut "Bagaimana Analisis Luas Ruangan Berdasarkan Kebutuhan Rak di Ruang Penyimpanan Berkas Rekam Medis Rawat Jalan di RSU Madani Medan 2019".

\section{METODE PENELITIAN}

A. Jenis Penelitian

Jenis penelitian ini menggunakan metode penelitian deskriptif kuantitatif yaitu penulis mengamati sumber penelitian untuk melihat langsung gambaran atau deskripsi tentang keadaan masalahnya secara objektif, kemudian menganalisa masalah tersebut dengan apa adanya (Natoatmodjo, 2010). Penelitian ini dilakukan pada bulan Februari - April 2019. Tempat penelitian dilaksanakan di bagian ruang penyimpanan rekam medis rawat jalan di Rumah Sakit Umum Madani Medan. Rumah Sakit Umum Madani Medan terletak di jalan A.R Hakim No. 168, kelurahan suka ramai, kecamatan Medan Area.

B. Subjek dan Objek Penelitian

Subjek dalam penelitian ini adalah ruang penyimpanan berkas rekam medis rawat jalan Rumah Sakit Umum Madani Medan. Objek dalam penelitian ini adalah berkas rekam medis rawat jalan dan rak penyimpanan rawat jalan Rumah Sakit Umum Madani Medan.

C. Variabel Penelitian dan Defenisi Operasional

Variabel penelitian adalah ukuran atau ciri yang dimiliki oleh anggota-anggota suatu kelompok yang berbeda dengan yang dimiliki oleh kelompok lain (Saryono, 2013). Adapun variabel-variabel yang akan diamati oleh peneliti adalah sebagai berikut :

1. Rata-rata kunjungan pasien

2. Rata-rata ketebalan berkas rekam medis

3. Ukuran rak penyimpanan

4. Jumlah kebutuhan rak penyimpanan

5. Ukuran luas ruangan

D. Defenisi Operasional

Defenisi operasional adalah untuk mendefenisikan variabel secara operasional yang diamati untuk memudahkan pengumpulan data dan membatasi ruang lingkup operasional (Saryono, 2008).

1. Rata-rata kunjungan pasien adalah jumlah pasien baru rawat jalan yang berobat ke rumah sakit.

2. Rata-rata ketebalan berkas rekam medis adalah ukuran tebal berkas rekam medis yang di ukur secara stematis.

3. Ukuran rak penyimpanan adalah ukuran rak penyimpanan berkas rekam medis rawat jalan yang dirumah sakit dihitung dengan menggunakan rumus matematika.

4. Jumlah kebutuhan rak penyimpanan adalah jumlah rak yang tersedia untuk menampung berkas rekam medis pasien.

5. Ukuran luas ruangan adalah ukuran ruangan penyimpanan rekam medis rawat jalan yang hitung dengan menggunakan rumus matematika.

E. Instrumen dan Cara Pengumpulan Data

Instrumen penelitian adalah alat atau fasilitas yang digunakan oleh peneliti dalam mengumpulkan data agar pekerjaannya lebih mudah dan hasilnya lebih baik (cermat, lengkap dan sistematis) sehingga lebih mudah diolah (Saryono, 2013). Maka 
instrumen yang akan digunakan dalam penelitian di Rumah Sakit Umum Madani Medan adalah sebagai berikut.

1. Pedoman Observasi

Pedoman observasi dalam penelitian ini berisi sebuah lembar checklist tentang jenis kegiatan yang akan diamati pada saat penelitian yaitu rak penyimpanan dokumen rekam medis, ruang penyimpanan dan jumlah dokumen rekam medis serta daftar kegiatan dalam mengetahui rata-rata ketebalan berkas rekam medis.

2. Pedoman Wawancara

Pedoman wawancara kepada kepala rekam medis untuk mengetahui jumlah pasien rawat jalan.

3. Menganalisis rak penyimpanan berkas rekam medis serta luas ruangan penyimpanan berkas rekam medis rawat jalan.

Adapun instrumen yang digunakan dalam menganalisis rak penyimpanan berkas rekam medis serta luas ruangan penyimpanan berkas rekam medis rawat jalan adalah:

1) Pulpen/pensil

2) Penggaris

3) Buku/kertas

4) Pita sentimeter

F. Cara Pengumpulan data

1. Observasi

Pengamatan langsung terhadap kebijakan-kebijakan dan prosedur tetap tentang sistem penyimpanan dan penjajaran di Rumah Sakit.

2. Pengukuran

Yaitu peneliti mengamati dan mengukur rak penyimpanan dokumen rekam medis rawat jalan untuk mendapatkan ukuran panjang, lebar, tinggi rak penyimpanan dokumen rekam medis serta mengukur luas ruangan penyimpanan berkas rekam medis rawat jalan di rumah sakit.

3. Sumber data

Data dalam penelitian ini adalah data yang berasal dari rak penyimpanan, dokumen rekam medis rawat jalan.

G. Teknik Pengolahan

Setelah data terkumpul maka dilakukan pengolahan data secara:

1. Collecting yaitu pengumpulan ukuran desain rak penyimpanan dokumen rekam medis di ruang filing.

2. Editing yaitu pengolahan data yang diperoleh dengan cara disusun menurut bagian yang diteliti agar dapat dibaca dilengkapi apabila belum sesuai dengan tujuan penelitian.

3. Tabulasi data yaitu proses pengolahan data yang dilakukan dengan cara memasukkan data kedalam tabel atau penyajian data dalam bentuk tabel untuk memudahkan pengelompokkan dan penghitungan data.

4. Penyajian data adalah suatu cara pengolahan data dengan cara menyajikan hasil dari pengumpulan data berupa teks atau narasi.

H. Analisi Data

Analisis data yang digunakan dalam penelitian ini adalah analisa data yang dilakukan secara deskriptif yaitu menggambarkan data yang terkumpul sebagaimana adanya tanpa bermaksud membuat kesimpulan yang berlaku untuk umum atau generalisasi (Isgiyanto, 2009). 


\section{HASIL DAN PEMBAHASAN}

\subsection{Hasil}

Berdasarkan penelitian yang dilakukan penulis mengenai "Analisis Luas Ruangan Berdasarkan Kebutuhan Rak di Ruang Penyimpanan Berkas Rekam Medis Rawat Jalan di RSU Madani Medan Tahun 2019" adalah perlu adanya pertambahan rak penyimpanan berkas rekam medis rawat jalan dan penataan luas ruangan penyimpanan berkas rekam medis rawat jalan.

\section{Rata-rata Kunjungan Pasien Rawat Jalan RSU Madani Medan}

Kunjungan pasien baru rawat jalan pertahun dapat dilihat pada tabel berikut:

Tabel 1. Jumlah Kunjungan Pasien Rawat Jalan Per-Tahun di RSU Madani Medan

\begin{tabular}{ccc}
\hline No & Tahun Kunjungan & Jumlah Dokumen Rekam Medis \\
\hline 1 & 2014 & 4.168 \\
\hline 2 & 2015 & 10.144 \\
\hline 3 & 2016 & 34.410 \\
\hline 4 & 2017 & 36.391 \\
\hline 5 & 2018 & 38.127 \\
\hline & Jumlah & $\mathbf{1 2 3 . 2 4 0}$
\end{tabular}

Berdasarkan tabel di atas jumlah dokumen rekam medis rawat jalan di RSU Madani Medan adalah 123.240 berkas.

\section{Rata-rata Ketebalan Berkas Rekam Medis}

Dari pengamatan dan pengukuran sebanyak 50 berkas rekam medis yang diperoleh dari 1 subrak penyimpanan rekam medis rawat jalan RSU Madani Medan, didapatkan rata-rata ketebalan berkas rekam medis yang diuraikan pada tabel berikut :

Tabel 2. Ketebalan Berkas Rekam Medis Rawat Jalan

\begin{tabular}{cccc}
\hline No & Ukuran Ketebalan BRM (cm) & Banyak Berkas & Jumlah Ketebalan \\
\hline 1 & 0.1 & 29 & 2.1 \\
\hline 2 & 0,2 & 12 & 2,4 \\
\hline 3 & 0,8 & 4 & 3.2 \\
\hline 4 & 0,9 & 4 & 3.6 \\
\hline 5 & 1,5 & 1 & 1,5 \\
\hline \multicolumn{4}{c}{ Rata-rata } \\
\hline
\end{tabular}

Berdasarkan tabel di atas rata-rata ketebalan berkas rekam medis rawat jalan di RSU Madani Medan yaitu 0,256 cm.

\section{Ukuran Rak Penyimpanan Rekam Medis RSU Madani Medan}

Berdasarkan hasil pengukuran yang dilakukan oleh peneliti terhadap rak penyimpanan yang tersedia di ruang penyimpanan berkas rekam medis rawat jalan di RSU Madani Medan dengan jumlah keseluruhan rak 8 unit dengan ketentuan masing-masing rak sebagai berikut:

a. 3 (tiga) rak terdiri dari 4 (empat) kolom dan 6 (enam) baris dengan panjang rak 265 $\mathrm{cm}$ dan lebar atau tinggi rak $280 \mathrm{~cm}$.

b. 3 (dua) rak terdiri dari 3 (tiga) kolom dan 5 (lima) baris dengan panjang rak $280 \mathrm{~cm}$ dan lebar atau tinggi rak $240 \mathrm{~cm}$.

c. 2 (dua) rak terdiri dari 6 (enam) kolom dan 7 (tujuh) baris dengan panjang rak $440 \mathrm{~cm}$ dan lebar atau tinggi rak $270 \mathrm{~cm}$. 
Tabel 3. Hasil Pengukuran Rak Penyimpanan Berkas Rekam Medis di RSU Madani Medan

\begin{tabular}{|c|c|c|c|c|c|c|}
\hline \multirow[b]{2}{*}{ Rak } & \multirow[b]{2}{*}{$\begin{array}{c}\text { Jumlah } \\
\text { Rak }\end{array}$} & \multicolumn{5}{|c|}{ Rak Penyimpanan Rekam Medis } \\
\hline & & $\begin{array}{c}\text { Jumlah Sub } \\
\text { Rak } \\
\text { Kesamping }\end{array}$ & $\begin{array}{c}\text { Jumlah } \\
\text { Sub Rak } \\
\text { Keatas }\end{array}$ & $\begin{array}{c}\text { Ukuran Sub } \\
\text { Rak } \\
\text { Kesamping }\end{array}$ & $\begin{array}{c}\text { Panjang } \\
\text { Rak }\end{array}$ & $\begin{array}{c}\text { Lebar } \\
\text { Rak }\end{array}$ \\
\hline $\mathbf{A}$ & 3 & 4 & 6 & $65 \mathrm{~cm}$ & $265 \mathrm{~cm}$ & $30 \mathrm{~cm}$ \\
\hline $\mathbf{B}$ & 3 & 3 & 5 & $90 \mathrm{~cm}$ & $280 \mathrm{~cm}$ & $30 \mathrm{~cm}$ \\
\hline $\mathbf{C}$ & 2 & 7 & 6 & $62 \mathrm{~cm}$ & $440 \mathrm{~cm}$ & $30 \mathrm{~cm}$ \\
\hline \multicolumn{2}{|c|}{ Jumlah } & 35 & 45 & $589 \mathrm{~cm}$ & $2515 \mathrm{~cm}$ & $30 \mathrm{~cm}$ \\
\hline \multicolumn{2}{|c|}{ Rata-rata } & 4 & 6 & $74 \mathrm{~cm}$ & $314 \mathrm{~cm}$ & $30 \mathrm{~cm}$ \\
\hline
\end{tabular}

Berdarkan tabel di atas jumlah rata-rata sub rak penyimpanan berkas rekam medis kesamping adalah 4 sub rak dengan ukuran $74 \mathrm{~cm}$ dan jumlah rata-rata sub rak keatas adalah 6 sub rak. Dengan ketebalan berkas rekam medis rata-rata $0,256 \mathrm{~cm}$, maka diperoleh jumlah berkas rekam medis di dalam 1 rak yakni:

$$
\begin{aligned}
& =4 \times(74 / 0,256) \times 6 \\
& =4 \times 289 \times 6 \\
& =6936 \text { RM dalam } 1 \text { Rak }
\end{aligned}
$$

Jadi jumlah berkas rekam medis dalam 1 rak sebanyak 6936 RM.

\section{Jumlah Kebutuhan Rak Berkas Rekam Medis Rawat Jalan RSU Madani Medan}

Dengan terjawabnya jumlah berkas rawat jalan dalam 5 tahun terakhir yakni 123240 berkas, dan jumlah berkas rekam medis dalam 1 rak adalah 6936 berkas, maka jumlah kebutuhan rak berkas rekam medis rawat jalan di RSU Madani Medan yaitu:

$$
\begin{aligned}
& =123240 / 6939 \\
& =18 \mathrm{rak} .
\end{aligned}
$$

Jadi, kebutuhan rak berkas rekam medis rawat jalan RSU Madani Medan adalah 18 rak.

\section{Kebutuhan Luas Ruangan Penyimpanan Berkas Rekam Medis RSU Madani Medan}

Berdasarkan observasi yang dilakukan di RSU Madani Medan ruang penyimpanan rekam medis terletak di belakang tempat pendaftaran pasien. Ruang penyimpanan yang ada saat ini terbagi dua yaitu ruang I panjangnya 3,85 meter lebar 3,30 meter dan ruang II panjangnya 4,70 meter dan lebar 1,32 meter sehingga total luasnya $18,99 \mathrm{~m}^{2}$.

Berdasarkan hasil observasi diketahui bahwa ruang penyimpanan rekam medis sempit, akses untuk 2 (dua) orang kurang, selain rak penyimpanan juga terdapat berkas rekam medis yang terletak di lantai. Jarak antara rak satu dengan yang lain ada yang berjarak $54 \mathrm{~cm}, 54$ $\mathrm{cm}, 52 \mathrm{~cm}, 74 \mathrm{~cm}$. Berikut adalah denah ruang penyimpanan rekam medis di RSU Madani Medan.

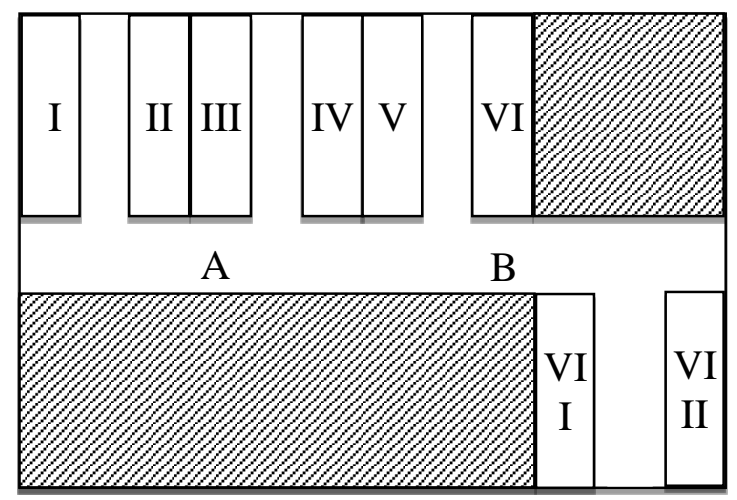

Gambar 1. Denah Ruang Penyimpanan Berkas Rekam Medis Rawat Jalan RSU Madani Medan 
Keterangan:

- I-VIII adalah rak penyimpanan berkas rekam medis

- A yaitu rak tempat penyimpanan formulir berkas rekam medis baru dicetak dan belum dirakit

- B adalah meja dan kursi pegawai rekam medis

- C adalah pintu masuk dan keluar ruangan penyimpanan berkas rekam medis

Tabel 4. Keterangan Gambar Denah Ruang Penyimpanan Berkas Rekam Medis RSU Madani Medan

\begin{tabular}{ccccc}
\hline Ket. & Jenis Rak & Panjang $(\mathbf{c m})$ & Lebar $(\mathbf{c m})$ & Ukuran Sub Rak \\
\hline I & Kayu & 265 & 30 & $65 \times 42 \mathrm{~cm}$ \\
\hline II & Kayu & 265 & 30 & $65 \times 42 \mathrm{~cm}$ \\
\hline III & Kayu & 265 & 30 & $65 \times 42 \mathrm{~cm}$ \\
\hline IV & Kayu & 280 & 30 & $90 \times 37 \mathrm{~cm}$ \\
\hline V & Kayu & 280 & 30 & $90 \times 37 \mathrm{~cm}$ \\
\hline VI & Kayu & 280 & 30 & $90 \times 37 \mathrm{~cm}$ \\
\hline VII & Kayu & 440 & 30 & $62 \times 36 \mathrm{~cm}$ \\
\hline VIII & Kayu & 440 & 30 & $62 \times 36 \mathrm{~cm}$ \\
\hline
\end{tabular}

Berdasarkan observasi di ruang penyimpanan rekam medis rawat jalan RSU Madani Medan, ruang penyimpanan tidak memungkinkan untuk penambahan jumlah rak baru, maka dari itu perlu perhitungan luas ruangan yang akan dipakai untuk menyimpan rekam medis dan tata letak yang perlu diperhatikan. Rak yang akan dibuat yaitu rak kayu yang mempunyai panjang rata-rata $314 \mathrm{~cm}$ dan lebar $30 \mathrm{~cm}$. Berikut merupakan gambar tata letak rak penyimpanan rekam medis:

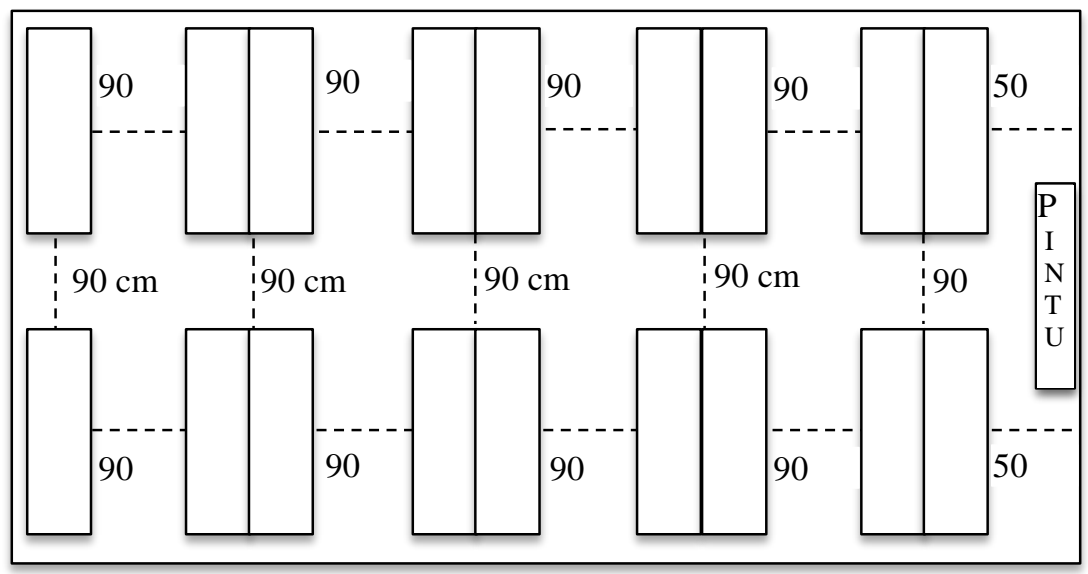

Gambar 2. Denah Ruang Penyimpanan

Perhitungan kebutuhan luas ruang penyimpanan dihitung dengan:

Panjang ruang $=($ Jarak antar rak $\mathrm{x}$ jumlah $)+($ Lebar rak $\mathrm{x}$ jumlah $)$

$$
\begin{aligned}
& =(90 \times 4)+(50 \times 1)+(30 \times 9) \\
& =(360)+(50)+(270) \\
& =680 \mathrm{~cm}=6,8 \mathrm{~m}
\end{aligned}
$$

Lebar ruang $=($ Jarak antar rak $x$ jumlah $)+($ Panjang rak $x$ jumlah $)$

$$
\begin{aligned}
& =(90 \times 1)+(314 \times 2) \\
& =(90)+(628)
\end{aligned}
$$$$
=718 \mathrm{~cm}=7,18 \mathrm{~m}
$$

Luas Ruangan $=$ Panjang Ruang $\mathrm{x}$ Lebar Ruang

$$
\begin{aligned}
& =6,8 \mathrm{~m} \mathrm{x} \mathrm{7,18} \mathrm{m} \\
& =48,82 \mathrm{~m}^{2}
\end{aligned}
$$


Luas ruang yang dibutuhkan untuk menyimpan 18 rak kayu dengan posisi seperti gambar 4.2 adalah $48,82 \mathrm{~m}^{2}$.

\subsection{Pembahasan}

\section{A. Rata-Rata Kunjungan Pasien}

Setiap harinya pasien terus bertambah dan berkas rekam medisnya betambah pula seiring dengan bertambahnya jumlah pasien setiap hari dan ketebalan berkas rekam medis di dalam rak penyimpanan akan bertambah pula. Berdasarkan hasil penelitian yang penulis lakukan di Rumah Sakit Umum Madani Medan bahwa rata-rata kunjungan pasien mulai dari tahun 2014-2018 yaitu berjumlah 123.240 orang. Dengan jumlah kunjungan pasien sebanyak 123.240, sesuai dengan pertambahan jumlah pasien baru setiap harinya, maka jumlah dan ketebalan berkas rekam medis akan bertambah pula sehingga akan berpengaruh kepada kebutuhan rak penyimpanan berkas rekam medis.

\section{B. Rata-Rata Ketebalan Berkas Rekam Medis}

Ketebalan berkas rekam medis akan terus bertambah setiap harinya seiring dengan bertambahnya pasien yang berobat ke rumah sakit. Semakin banyak pasien baru yang datang berobat ke rumah sakit maka semakin bertambah pula jumlah berkas rekam medis didalam rak. Sesuai dengan hasil penelitian di Rumah Sakit Umum Madani Medan, ukuran ketebalan berkas rekam medis yang berjumlah 50 berkas adalah 12,8 cm. dengan rata-rata ukuran untuk satu berkas rekam medis adalah $0,256 \mathrm{~cm}$.

\section{Ukuran Rak Penyimpanan Berkas Rekam Medis}

Di Rumah Sakit Umum Madani Medan terdapat 8 (delapan) unit rak dengan ukuran dan jumlah sub rak yang berbeda-beda. Dengan ukuran dan jumlah yang berbeda-beda tersebut, peneliti mengambil jumlah rata-rata dari 8 unit rak tersebut yakni jumlah sub rak kesamping adalah 4 sub rak dengan ukuran rata-rata $74 \mathrm{~cm}$ dan jumlah rata-rata sub rak keatas adalah 6 sub rak. Panjang rata-rata 8 unit rak adalah $314 \mathrm{~cm}$. Dengan ketebalan berkas rekam medis rata-rata $0,256 \mathrm{~cm}$, maka diperoleh jumlah berkas rekam medis di dalam 1 rak yakni 6936 RM dalam 1 Rak. Dengan jumlah tersebut, jika dilihat dari jumlah berkas rekam medis dalam 5 tahun terkhir sebanyak 123.240 berkas maka bisa diprediksi bahwa jumlah rak masih kurang.

\section{Jumlah Kebutuhan Rak Penyimpanan}

Jika dalam suatu rumah sakit rak penyimpanan cukup, maka semua berkas rekam medis akan termuat dalam rak tersebut sehingga berkas rekam medis akan tersusun rapi, mempermudah dan mempercepat ditemukan kembali berkas rekam medis yang disimpan, mudah mengambil dan mudah pengembaliannya serta melindungi berkas rekam medis dari kerusakan fisik. Sebaliknya jika rumah sakit kekurangan rak, sebagian berkas rekam medis tidak akan termuat dalam rak dan diletakkan dilantai akibatnya memperlambat petugas dalam pengambilan berkas rekam medis dan berkas rekam medis berpeluang terjadinya kerusakan fisik.

Berdasarkan perhitungan prediksi kebutuhan rak penyimpanan berkas rekam medis rawat jalan saat ini adalah 18 unit rak. Jika saat ini rumah sakit memiliki 8 rak, maka rumah sakit perlu menambah 10 rak lagi agar kebutuhan rak dapat tercukupi dan dapat menampung semua berkas rekam medis pasien secara sistematis dan tidak menyulitkan petugas dalam pencarian berkas rekam medis pasien. Penambahan rak juga hendaknya disesuaikan dengan luas ruangan penyimpanan, agar rak yang dibutuhkan dapat tertata secara teratur sebagaimana mestinya. 
E. Kebutuhan Luas Ruangan Penyimpanan Berkas Rekam Medis RSU Madani Medan

Ruang Penyimpanan di Rumah Sakit Umum Madani Medan yang ada saat ini terlalu sempit, akses untuk 2 orang kurang sehingga petugas harus bergantian melakukan pengambilan dan pengembalian berkas rekam medis serta jarak antar rak yang berbeda dan banyaknya rak yang ada di ruangan. Luas ruang penyimpanan yang ada saat ini yaitu $18,99 \mathrm{~m}^{2}$ dengan luas tersebut tidak memungkinkan untuk penambahan jumlah rak baru karena keterbatasan ruangan yang ada. Rumah Sakit Umum Madani Medan belum pernah melakukan perhitungan kebutuhan luas ruangan penyimpanan. Perhitungan luas ruang penyimpanan dapat ditentukan setelah diketahui jumlah rak yang dibutuhkan dan menentukan jarak antar rak, untuk menampung 18 unit rak baru yang jarak antar raknya $90 \mathrm{~cm}$ telah diperhitungkan luasnya yaitu $48,82 \mathrm{~cm}^{2}$. Idealnya lorong untuk rak penyimpanan adalah 80-100 cm sehingga dalam penelitian ini menggunakan $90 \mathrm{~cm}$ (Rustiyanto, 2011). Jarak ini juga sesuai menurut Depkes 2006 bahwa jarak antara 2 (dua) buah rak untuk lalu lalang dianjurkan selebar $90 \mathrm{~cm}$. Jarak yang ideal memudahkan akses jalan petugas filing yang mengambil dan menyimpan rekam medis.

\section{KESIMPULAN}

1. Jumlah rak penyimpanan berkas rekam medis rawat jalan yang ada di Rumah Sakit Umum Madani Medan saat ini adalah 8 rak. Berdasarkan hasil perhitungan rata-rata jumlah kunjungan pasien baru dari tahun 2014-2018 sebanyak 123.240, rata-rata ketebalan berkas rekam medis yakni $0.256 \mathrm{~cm}$, dan jumlah berkas rekam medis dalam 1 rak sebanyak 6936 yang dilakukan dirak penyimpanan, RSU Madani Medan diprediksi membutuhkan rak penyimpanan sebanyak 18 rak.

2. Ruang penyimpanan rekam medis di Rumah Sakit Umum Madani Medan saat ini terbagi dua yaitu ruang I panjangnya 3,85 meter lebar 3,30 meter dan ruang II panjangnya 4,70 meter dan lebar 1,32 meter sehingga total luasnya 18,99 $\mathrm{m}^{2}$ luas adalah $12,96 \mathrm{~m}^{2}$. Berdasarkan hasil dari perhitungan luas ruang penyimpanan rekam medis di Rumah Sakit Umum Madani Medan diketahui dari jarak antar rak jarak antar rak $90 \mathrm{~cm}$ maka luas ruang penyimpanan yang dibutuhkan untuk menyimpan 18 unit rak baru jenis kayu adalah $48,82 \mathrm{~m}^{2}$.

\section{REFERENCES}

Arikunto. 2010. Manajemen Penelitian. Jakarta: Rineka Cipta.

Depkes RI. 2006. Pedoman Penyelenggaran dan Prosedur Rekam Medis Rumah Sakit. Jakarta: Direktorat Jendral Bina Pelayanan Medik.

Dirjen Yanmed. 2006. Pedoman Penyelenggaraan dan Prosedur Rekam Medis Rumah Sakit di Indonesia Revisi II. Jakarta.

Lubis, S. P. S., \& Handayani, J. (2018). Tinjauan Kebutuhan Rak Penyimpanan Berkas Rekam Medis Untuk 5 Tahun Kedepan Di Rumah Sakit. 3(1), 404-408.

Notoadmodjo, S. 2012. Metodologi Penelitian Kesehatan. Jakarta: Rineka Cipta.

Peraturan Menteri Kesehatan No. 269/Menkes/Per/III/2008 tentang Rekam Medi. 
Putri, dkk. 2015. Analisis Tata Ruang Tempat Penyimpanan Dokumen Rekam Medis Pasien Ditinjau dari Aspek Antropometri Petugas Rekam Medis. http://Jmiki.aptirmiki.or.id. Diakses pada tanggal 10 Februari 2019.

Rustiyanto, 2011. Manajemen Filing Dokumen Rekam Medis dan Informasi Kesehatan. Yogyakarta: Politeknik Kesehatan Permata Indonesia.

Ritonga, Z. A., \& Ritonga, N. A. (2018). Analisa Kebutuhan Rak Penyimpanan Berkas Rekam. 3(1), 417-424.

Saryono. 2013. Metodologi Penelitian Kualitatif dan Kuantitatif dalam Bidang Kesehatan. Yogyakarta: Graha Ilmu.

Silalahi, P. (2016). Tinjauan Prosedur Penyimpanan Berkas Rekam Medis di Rumah Sakit Jiwa Provinsi Sumatra Utara Tahun 2015. Jurnal Ilmiah Perekam Medis Dan Informasi Kesehatan, STIKes Imelda Medan, 1(1), 7-12.

Sugiyono, 2013. Metodologi Penelitian Pendidikan Pendekatan Kualitatif dan Kuantitatif. Bandung: Alfabeta

Undang-undang No. 29 tahun 2004 Tentang Praktik Kedokteran.

\section{BIOGRAPHIES OF AUTHORS}

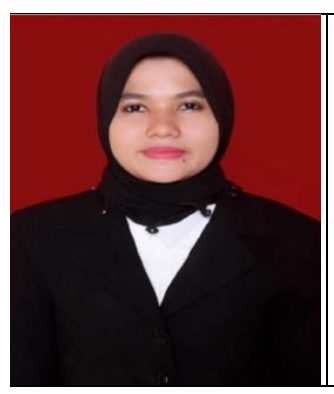

Puput Melati Hutauruk, Gelar Sarjana diperoleh dari Universitas Sari Mutiara Indonesia, Jurusan Administrasi Kebijakan Kesehatan (AKK) pada Tahun 2014. Magister Kesehatan Masyarakat diperoleh dari Universitas Sari Mutiara Indonesia, Jurusan Komite Akreditasi Rumah Sakit (KARS) pada Tahun 2017. Saat ini aktif sebagai pengajar di Program Studi D-IV Manajemen Informasi Kesehatan Universitas Imelda Medan. 